\title{
Stationless in Sydney: The Rise and Decline of Bikesharing in Australia
}

Capucine Heymes

Keywords: sharing economy, transport, bicycle, stationless, public bicycle, dockless, bikesharing

https://doi.org/10.32866/7615

\section{Transport Findings}

In mid-2017, stationless, (or dockless) bikesharing appeared on the streets of Sydney. The birth of dockless bikesharing, its evolution as well as its consequences, and use habits are studied with review of policies and field investigations. A systematic analysis of the company apps, along with field investigations found that most bikes are not used most days, up to $50 \%$ are vandalized, fewer than $15 \%$ had the mandated helmet, and many were mislocated according to the GPS. Bikesharing use in Sydney is less than hoped for, vandalism is high, regulations unfavourable, and thus, the conditions for success remain unmet.

\section{RESEARCH QUESTION AND HYPOTHESIS}

Stationless bikesharing systems have been emerging on most continents since 2014, and especially since 2017, following several decades of development (DeMaio 2009; Shaheen, Guzman, and Zhang 2010). Issues like vandalism, which confronted the first generation of bikesharing (Amsterdam's White Bikes) confront this fourth generation bikesharing system and are compounded with new issues of visual pollution and congestion in public spaces. Consequently, bikesharing has been rejected by some governments and residents (Ehrenkranz 2018; Zhou 2017).

This study investigates the deployment of dockless bikesharing in Sydney in the 2017-2018 period (Figure 1). Four dockless bikesharing companies operated in Sydney during the period of study:

- Ofo (est. April 2014, Beijing) claimed 600 bikes in Sydney and was the first dockless bikesharing system to appear there. Its almost ten million yellow bikes generated over six billion bike trips, according to the company. It landed in Sydney in October 2017, but it announced the end of its Australian operations (in Sydney and Adelaide) on July 10, 2018 (9news 2018; Daly 2018; Gorrey 2018; Joyce 2018; Ofo 2018).

- oBike (est. November 2016, Singapore) claimed 1,000 bikes in Sydney. It landed in Melbourne during the summer of 2017. Its arrival was criticized, bikes were heavily vandalized, and the Victoria 


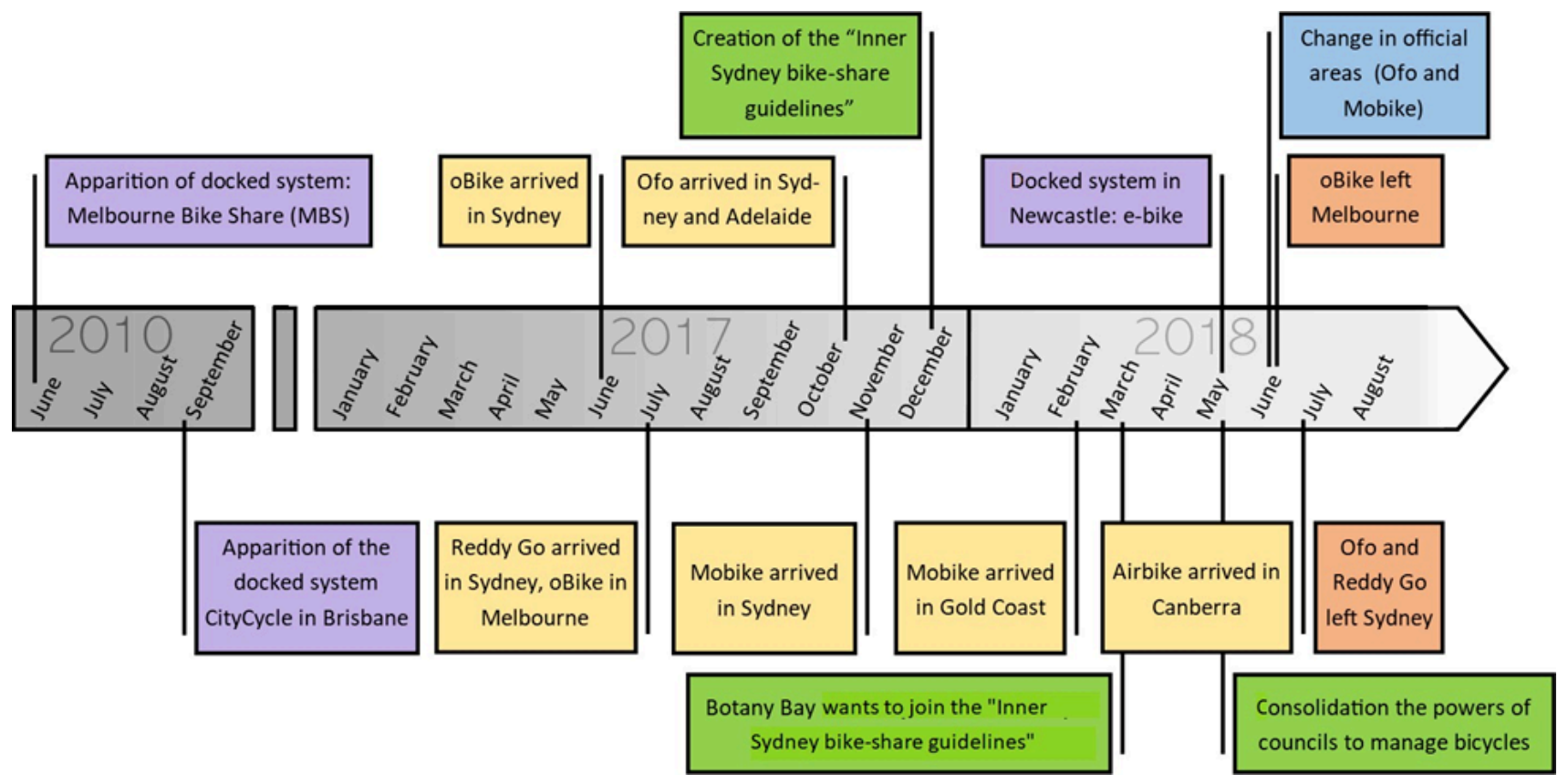

Figure 1: Timeline for the Introduction and Evolution of Bikesharing Systems in Australia

Environment Protection Authority threatened large fines if the company didn't clean damaged bikes. All this led to its departure in June 2018. The yellow bikes operator was still operating in Sydney as of July 2018, but its longevity is uncertain and it appears to have withdrawn from the market (abc.net 2018; oBike 2018; Sas 2018).

- Mobike (est. January 2015, Beijing) now owns ten million orange bicycles globally. It was the last company to arrive in Sydney in November 2017 and claims 500 bikes there, though this number appears to be an underestimate (Mobike 2018).

- ReddyGo (est. 2017, Sydney) was the only homegrown company seriously competing for market share but, like Ofo, it announced its departure on July 10, 2018. It claimed 2,000 bikes but this claim is questionable (9news 2018; Joyce 2018; ReddyGo 2018; Zhou 2017).

Bicycles and bicyclists are scarce on the automobile-oriented streets of most Australian cities, with a regionwide mode-share of under $1 \%$ for work trips (Loader 2012). Sydney, in New South Wales, has several regulations that are considered antibicyclist including mandatory helmet laws and high fines for violations by bicyclists. Sydney also lacks a well-developed separated bike path or bike lane network, which has been found to support bicycle demand elsewhere (Schoner and Levinson 2014). 


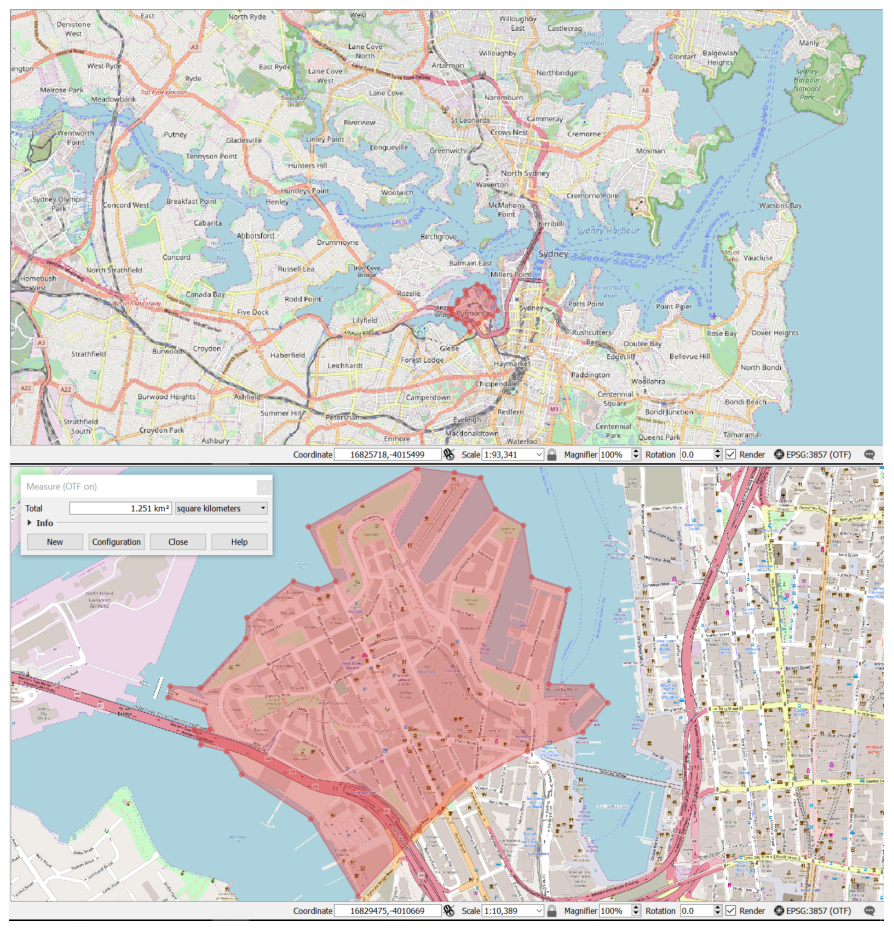

Figure 2: Sydney and the Peninsula of Pyrmont (top). Detail of Pyrmont (bottom)

When shared bikes arrived in their territories the Canada Bay, City of Sydney, Inner West, Randwick, Waverley, and Woollahra councils (local government units) came together to create the Inner Sydney Bike Share Guidelines (Cormican 2017; Sas 2018), which added to the cost of bikesharing operations.

\section{METHODS AND DATA}

Despite repeated requests, none of the above companies were willing to share bike location or utilization data. Therefore, the data here comes from manually scraping screenshots of bikesharing apps and from field investigations.

A focused study of the Pyrmont area measures the use and mobility of the bikes by company, as shown in Figure 2. Phone apps were used to gather the most accurate data. Each company has its own app on which we can see the bikes within a geographic perimeter. For one month, screenshots taken from each company's app every four hours located the bikes within this specific perimeter. Afterward, the number of bikes was noted and recorded. We gathered several kinds of information including the distribution of the companies in a specific area and the percentage of stationary bikes (bikes that did not move between measurements).

While each company has its own area of operation, they all serve central Sydney and their areas tend to overlap. The Pyrmont peninsula, an urban (and in part tourist) area was chosen for in-depth research. The water provides a natural boundary and delimits the area, and Pyrmont contained a sufficient number of bikes to produce interesting results. 


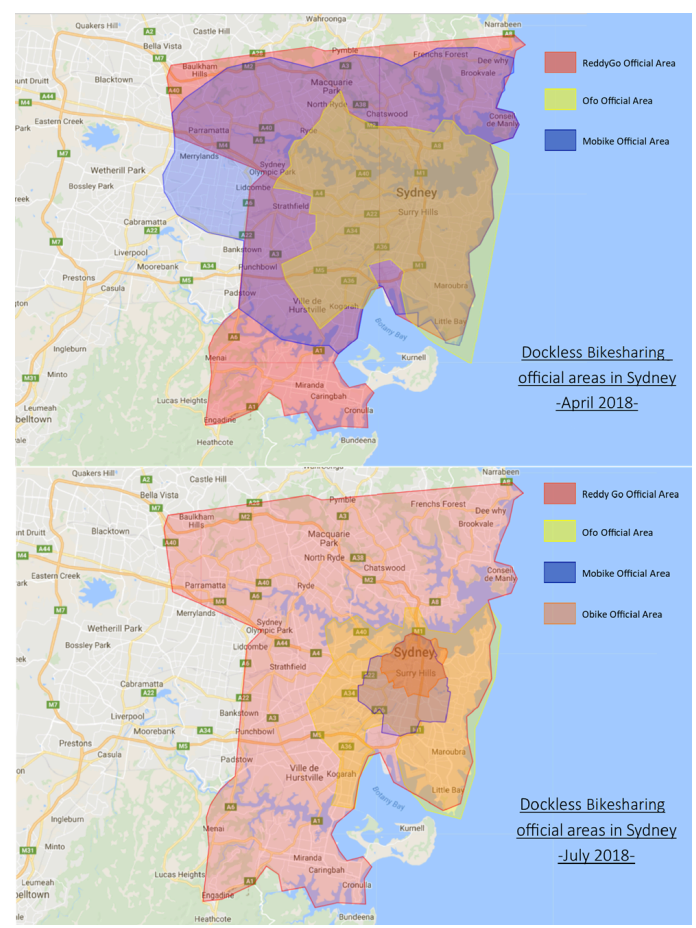

Figure 3: Map of the Dockless Bikesharing Companies in Sydney in April (top) and July (bottom) of 2018

For this analysis, we assumed that all the bikes were accurately represented by the apps (i.e., all the bikes were in the apps and all the bikes reported by the app existed in the field at the reported locations), though we tested that assumption later.

The operating areas changed over time. In April 2018, three companies (excluding oBike) reported their own official operating areas within the app, and by July 2018 all four companies reported boundaries for the use of their bikes, as shown in Figure 3. Ofo and Mobike reduced their areas to control the geographic spread of bikes, ReddyGo did not.

\section{FINDINGS}

Figure 4 shows the share of bikes in the same location on the Pyrmont peninsula for 24 and 48 hours, respectively. The two graphs highlight which company had the most mobile bikes. But, since the number is a percentage, it depended on the number of bikes that the companies left at disposal. For example, Ofo had, on average, the smallest percentage of static bikes, but it also had the fewest bikes in Pyrmont (shares during the study were: Mobike 45\%, oBike 34\%, ReddyGo 16\%, Ofo 5\%). However, Mobike represented almost half of the bikes available on the peninsula and, at the end of the experiment, had the smallest percentage of static bikes. So, either its bikes were better used, or the company regularly moved and redeployed its bikes. We did not observe the latter. 

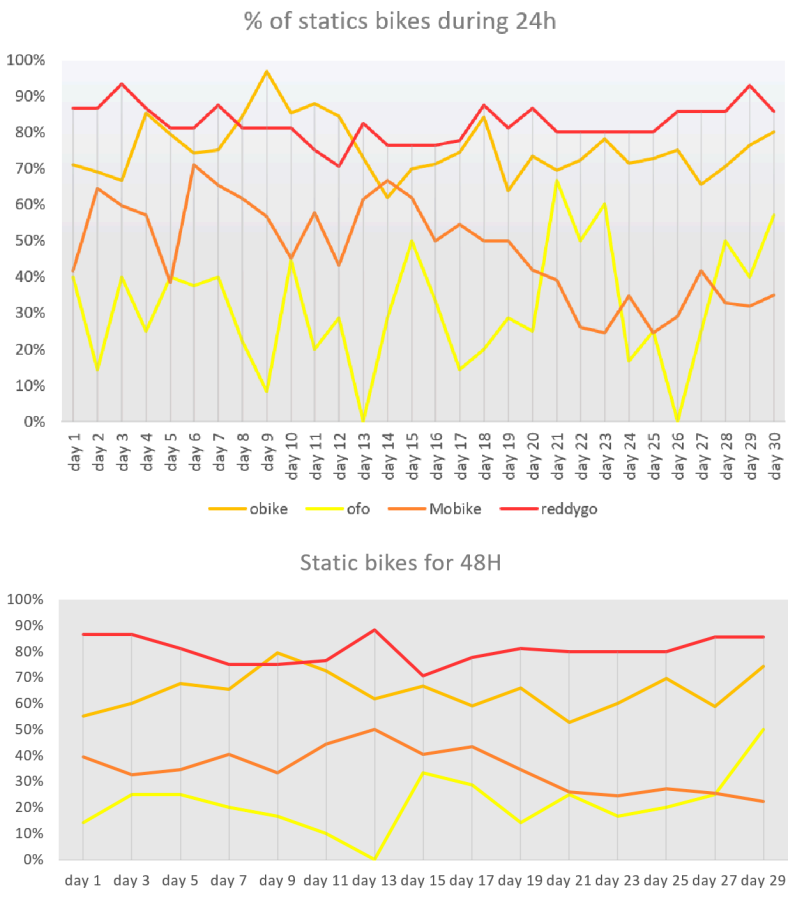

—obike - ofo - Mobike —reddygo

Figure 4: One-day (top) and Two-day (bottom) Percentage of Unmoved Bikes in Pyrmont by Dockless Bikesharing Company

Consistent with the graphical intuition, a Fisher test to verify the difference of the variances and a Student's t-test corroborate that all the companies differed in their percent static at a p-value of $5 \%$.

ReddyGo did not have a large dispersion range; apart from a few exceptions, the number of static bicycles during four-hour periods remained between $81 \%$ and $87 \%$ when its median was at $86 \%$. Ofo had the largest variation: its first quartile was at $40 \%$, its third at $67 \%$, and its median at $50 \%$. There were no strong trends by day of the week.

The mobility of the bikes is one of the most important data points for the dockless bikesharing system; it represents the use of the system and retention of riders. This study shows that shared bikes were not moving (and thus not being used) as much as expected or hoped for by the companies deploying bikes. Indeed, Australia is one of the countries with the lowest rate of trips per bike and per day: only 0.3 compared to 2-6 for countries overseas (9news 2018).

Table 1 provides the results of an in-person inspection by the research team of nearly 400 deployed bikes on the streets of Sydney. Results show that oBike and ReddyGo bikes were the most vandalized: $34 \%$ and 50\% respectively, and that Mobike bikes were first when it came to helmet retention; $14 \%$ of these bicycles had helmets. Finally, field investigations highlighted that all the companies had GPS tracking defects which ranged from $67 \%$ at ReddyGo to $10 \%$ at Ofo. 
Table 1: Comparison of Bikesharing Systems

\begin{tabular}{lllll}
\hline & oBike & Ofo & Mobike & ReddyGo \\
Deposit & $\$ 69.00$ & $\$ 0.00$ & $\$ 1.00$ & $\$ 99.00$ \\
30-minute ride & $\$ 1.99$ & $\$ 1.00$ & $\$ 1.20$ & $\$ 1.99$ \\
\hline Total bikes in Sydney (claimed) & 1,000 & 600 & 500 & 2,000 \\
Average bikes in Pyrmont (observed) & 34 & 5 & 44 & 15 \\
Bikes used daily in Pyrmont (observed \%) & $25 \%$ & $68 \%$ & $53 \%$ & $18 \%$ \\
Vandalized bikes (field observation) & $3 \%$ & $34 \%$ & $10 \%$ & $50 \%$ \\
With helmet (field observation) & $14 \%$ & $3 \%$ & $10 \%$ & $0 \%$ \\
GPS defects (field observation) & $22 \%$ & $31 \%$ & $10 \%$ & $67 \%$ \\
\end{tabular}

These results help explain why two of the four companies operating in Sydney decided to leave the city in July 2018: the low rate of trips-per-day per bike, a high level of vandalism, and the threat of heavy fines from councils made the system one without potential for financial profit. While dockless bikesharing appears to be successful in many cities globally, the factors leading to its success have not been replicated in Sydney to date.

In November 2018, LimeBike entered Sydney with stationless eBikes. 


\section{REFERENCES}

9news. 2018. "Ofo Bike-Sharing Company to Close in Australia.” 9 News. https://www.9news.com.au/national/2018/07/10/08/02/ofo-bike-sharing-company-to-close-inaustralia.

abc.net. 2018. "OBike to Leave Melbourne after Crackdown on Bicycle Share Company.” ABC News. https://www.abc.net.au/news/2018-06-12/obike-dockless-bicycle-scheme-to-leavemelbourne/9860314.

Cormican, L. 2017. "Bike Sharing Companies Have Three Months to Comply with New Council Rules.” Sydney Morning Herald. https://www.smh.com.au/national/nsw/bike-sharing-companieshave-three-months-to-comply-with-new-council-rules-20171219-h070vi.html.

Daly, N. 2018. "Bike-Sharing Company Ofo Cycles out of Australia, Others Remain in Doubt." ABC News. https://www.abc.net.au/news/2018-07-10/ofo-share-bikes-cycle-out-of-australiaother-operators-in-doubt/9962236.

DeMaio, P. 2009. "Bike-Sharing: History, Impacts, Models of Provision, and Future.” Journal of Public Transportation 12 (4): 3 .

Ehrenkranz, M. 2018. “Can People Ever Be Trusted with Dockless Bike Sharing?” Gizmodo. https://gizmodo.com/can-people-ever-be-trusted-with-dockless-bike-sharing-1823355560.

Gorrey, M. 2018. "Bump in the Road as Bike Share Operators Reddy Go, Ofo Quit Sydney." Sydney Morning Herald. https://www.smh.com.au/national/nsw/bump-in-the-road-as-bike-shareoperators-reddy-go-ofo-quit-sydney-20180710-p4zqm1.html.

Joyce, E. 2018. "Bike Share Companies Reddy Go and Ofo Are Leaving Sydney.” Timeout Sydney. https://www.timeout.com/sydney/news/bike-share-companies-reddy-go-and-ofo-are-leavingsydney-071018.

Loader, C. 2012. "Trends in Journey to Work Mode Shares in Australian Cities to 2011." Charting Transport. https://chartingtransport.com/2012/10/30/trends-in-journey-to-work-mode-shares-inaustralian-cities-to-2011/.

Mobike. 2018. Homepage. 2018. https://mobike.com/us/.

oBike. 2018. Homepage. 2018. https://www.o.bike/.

Ofo. 2018. Homepage [Company and Website Are No Longer Operational]. 2018.

https://www.ofo.com/.

ReddyGo. 2018. Homepage. 2018. https://www.reddygo.com.au/.

Sas, N. 2018. "Bike-Sharing Phenomenon Set to Stay in Sydney, but for How Long?" ABC News. https://www.abc.net.au/news/2018-06-27/bike-sharing-still-going-in-sydney-but-for-how-long/ 2910914.

Schoner, J.E., and D.M. Levinson. 2014. "The Missing Link: Bicycle Infrastructure Networks and Ridership in 74 US Cities.” Transportation 41 (6): 1187-1204.

Shaheen, S., S. Guzman, and H. Zhang. 2010. "Bikesharing in Europe, the Americas, and Asia: Past, Present, and Future." Transportation Research Record:Journal of the Transportation Research Board, no. 2143: 159-167. 
Zhou, N. 2017. "Dockless Bike Share: Privacy and Safety Concerns Voiced Ahead of Sydney Launch.” The Guardian. https://www.theguardian.com/australia-news/2017/jun/25/docklessbike-share-privacy-and-safety-concerns-voiced-ahead-of-sydney-launch. 